\title{
The Role of Humorous Initiative Advertisement in Film and Television Advertising*
}

\author{
Haiying Chen \\ School of Communication and Animation \\ Qingdao University of Science \& Technology \\ Qingdao, China
}

\begin{abstract}
The paper analyzes the types of humor in TV commercials, including regular humor, cold humor and absurd humor. Through these types of case studies, consumers can deeply understand the benefits of using these kinds of humor to make advertisement. At the end, this paper analyzes the role of humorous advertising from the perspective of consumers and aesthetics. Nowadays, more and more companies like to use this method to make advertisements.
\end{abstract}

Keywords — cold humor; curiosity; creative point; absurd

\section{INTRODUCTION}

More and more companies like to use humor to make advertisements, which mainly impress consumers through emotional appeals. The consumers can watch the advertisements without any pressure, and appreciate it as post-meal topic of conversation. In daily life, people often imitate the movements and intonation of TV commercials to enjoy each other.

\section{ThE DEFINITION OF HUMOROUS INITIATIVE ADVERTISEMENT}

Humorous advertising is a shining point in many forms of advertising. It belongs to a category of comedy. With the methods of metaphor, exaggeration, symbol, implication, pun, homophony and harmony, it would use witty and concise language to disclose, criticize and laugh at unreasonable, contradictory things or phenomena in social life. People would negate these things or phenomena with smiles.

Humorous advertisement creativity should fully consider the psychology of the target audience. It should take goods or services as the core appeal. It is meaningful. From an aesthetic point of view, advertising is designed to be fun and engaging.

\section{TYPE OF HUMOROUS ADVERTISING}

\section{A. Ordinary Humor}

This type of advertising allows people to feel the characteristics of implicit humor in a normal way of thinking

*2014 Humanities and Social Sciences Research Funding Project of Qingdao University of Science and Technology: No. 14XB06 in the usual advertising.

\section{- Budweiser Beer Advertising}

For the classic Budweiser beer advertisement, the owner walked in the manor with a bottle of beer. After a small group of ants found the beer in his hand, they carried a rake, and a small ant took the small butt and moved the rake. It was designed to be able to hit people. The manor was hit by the rake. And the little ants got the beer and left. The advertisement describes the ants' singularity and spoofing actions, and the humor and taste are fully reflected in the picture.

\section{- Yellow page advertising I}

The trousers of a man standing in the middle opened, and he kept trying to find a place to hide. He tried to face the street, leaning against the wall. However, he didn't expect that there were a lot of people who could look out and saw his awkward movements behind the glass wall. Then, he came to the phone booth to help a girl pick up the things. It would reveal his flaws... In the phone booth, he hurriedly leafed through the yellow pages, and called the phone...The advertising has undoubtedly extended aesthetic time of the audience. The audiences are full of curiosity and joy, and they always want to see it...

- Yellow Page Advertising II

A man was about to wash his hands. And his hands were covered with foam. At this time, the phone rang. The man rushed over and hit the debris on the way. The man showed painful expression. The man picked up the phone, and the other party had hung up. When the man continued to wash, the phone rang again when the face was full of foam. The man was helpless, and the other two old people on the phone were laughing, which is obviously a prank for the two old people.

The advertisement expresses the convenience of the yellow page of the phone in a humorous way. The scene at the beginning of the advertisement is attractive, and let the audience watch it. And then, the phone rang. The state of man's embarrassment gave the audience a relaxed atmosphere. It is naturally close to life. The whole advertisement is clear in thinking. 


\section{B. Cold Humor}

Cold humor deliberately makes important things be simple with using restrained expression way. And it would make serious things to be jokes. The second half of cold humor can't be guessed. However, the curiosity will make the listener guess. In the end, that is the attention of the audience and the input of thinking. This process of lengthening or deepening the mind unwittingly instills the product into the audience's mind. And the audience will pay attention to the product in the process of expectation. Such advertisements are highly unfamiliar. The time for customers to think or watch is longer, and the value of advertisements is greater.

\section{- "Guinness Beer - Fish and Bicycle"}

Advertisements show the characteristics of feminism, using the popular saying in the West that "women need men, just like fish need bicycles." Groups of laughing women play darts, drink Guinness beer, and enjoy the pleasure of relaxing after a day of work. The camera is switched, and a car is coming on the road. The driver is also a woman. They took the bags, and planned to have a drink at the bar...the things that the man had done, the women were very good at it. They found an unmarried woman to be a spokesperson. The woman insisted that women can live independently without relying on men. No one can expect that the woman would marry at the age of 66 years old. The advertisement cleverly uses Gloria Steinam's famous sayings and her personal experiences as creative points. The humor ridiculously and humorously uses the sexual relations to metaphorize the black and white of the Guinness beer.

\section{Black Humor}

1) Source of black humor: It is an important literary genre in the United States in the 1960s and 1970s. In 1940, the French surrealist Breton published the book "Black Humor Collection". However, the word became popular in the 1960s. In March 1965, Friedman compiled a collection of short stories. It collected the articles of 12 authors. And the title is "Black Humor". And the word "black humor" came from this. It is one of the most representative schools of American novels in the 1960s.

2) Definition of black humor: According to the explanation for "black humor", "A desperate humor tries to draw people's laughter as a response to human beings' apparently insignificance and absurdity in life." Black humor is a literary method of expressing tragedy in the form of comedy. Nick Burke once gave an example to explain the definition and nature of black humor in a popular way. Before the hanging, a person who was sentenced to hangs pointed to the gallows and asked the executioner: "Are you sure that this stuff is strong?" Therefore, black humor is also known as "humor under the gallows". As a form of aesthetics, "black humor" belongs to the category of comedy. However, it is also a metamorphosis comedy with tragic color.
3) The advertisement of mushroom and meat sauce: At first, a little apprentice gave the master a meal. And the master felt good after eating. The little apprentice asked what was added in the rice. After the little apprentice took out the sauce, the master felt very angry when he saw the meat. When he was to hit the little apprentice, the little apprentice hurriedly said that this was not made of meat.

The expression used in the advertisement made the audience feel the delicious taste of the sauce. The audience's taste was materialized. And the audience could not help but swallow and have a taste. It would form good advertising effect, and greatly promote the product.

\section{- Canal TV Advertising}

This idea was taken for the French Canal TV. And the creative idea uses the mode of narration and conclusion entering in the theme. The first half of the story is very urgent. The flood is coming soon. And the people who can retreat are taking the time to Noah's Ark. Human beings carried various species on board to survive. At this time, the unicorn was found to be lost. She sent a shepherd to look for it. After hardships and difficulties, it plucked the mountains and waded, and finally found the unicorn. When he was able to be relaxed, the accident happened. This is also the climax of the story. He was unusually surprised. When identifying the sex of the unicorn, it was found that the two unicorns are unable to reproduce the offspring. And it explains why the unicorn is extinct.

And then, people can see the male protagonist pleasing the hostess. This is the male's improvisation of the unicorn on the heroine. And the canal+ TV station is compared to the man in the advertisement. This shows that the Canal+ TV program has high-level creativity. "We all love to make stories and see Canal+ for more stories."

\section{Absurd Humor}

From the perspective of etymology, the word "absurd" comes from the Latin "absurdus", meaning out of tune or senseless. Its prefix $a b$ is to strengthen the tone, and the suffix "surdus" means "deaf" or be muffled. It is originally a musical term. It means that the music is discordant and uncoordinated. Later, its meaning extends to be untrue, irrational, illogical, and unreasonable. It was introduced as the incompatibility among people or between the human and the environment. The application of modern advertising is based on the irrationality. It is clearly contrary to common sense. Therefore, it is the definition of stupidity.

\section{- TJOY sunscreen advertisement}

The advertisement combines the girls who have secretly been loved in the campus with the vampires. The picture is beautiful. The male protagonist followed Jiayi. And they went to the residence. He found that Jiayi should be a vampire. In order to pursue happiness, he hoped to be with her forever. However, he was worried that Jiayi should not see the light during the day. And the male protagonist did not show up. At this time, Jiayi immediately take out Ding TJOY sunscreen. In the end, the advertisement slogan 
appeared. New generation of TJOY sunscreen contains whitening ingredients ginseng active cells. With doubleeffect sunscreen anti-plaque factor, it could inhibit melanin production; dilute the formed pigmentation, and whitening the skin. And people can't be afraid of the strong direct sunlight. The vampire's skin is so perfect.

\section{THE ROLE OF HUMOROUS ADVERTISING}

Humor can make people get rid of psychological resistance and relax the vigilance. Moreover, humor is pleasant experience. In this type of advertising, it is also a point of shaping certain sensation. For example, in the McDonald's advertisement, the baby is in the rocking chair. He saw McDonald sign, and he would laugh. And he would cry when he can't see the sign. This type of advertising is simple and easy to be constructed, making it easy for people to remember the brand.

Humorous advertisements can stimulate people's desires. Experimental data shows that when people are in a good mood, more blood will flow into the brain, which will make them happy. And it is good for their health.

The unique aesthetic characteristics and aesthetic value of humorous advertisements promote the dissemination of advertising information. Humor is more in line with the psychological needs of contemporary people. The design of the modern era has shaken off the shackles of traditional single thinking and diversified communication development, and aroused the participation and intervention of the audience. Its novel and diversified expression method reflects new, different and strange design concept of contemporary design. The design concept is changeable. It can reduce people's depression and anxiety, and give people a relaxed and happy feeling. Humorous advertisements include deep meanings in the fun and wit. People can unwittingly accept the others' opinions in a relaxed and enjoyable spiritual enjoyment. As Mr. Qian Zhongshu said, "Humor is to have a heart. No matter how much time and space are apart from each other, people would look at each other and smile.

It can lighten the utilitarian of advertisement. From the perspective of aesthetics, the most basic premise is to free the utilitarian relationship between spiritual freedom and things and to make the mind as free as possible. Humor expresses the sharpness and ingenuity of the creative subject through relaxed and witty plot, which makes the advertisement, is full of rich emotional color and artistic beauty. Thus, it would dilute the direct utilitarian impression of advertising, and make people accept the advertising information with the infection and enjoyment of art. And then, it would achieve the natural communication.

\section{CONCLUSION}

Humorous advertising enhances the taste of advertising. Humorous advertising is the crystallization of wisdom. It has the characteristics of artistry, temperament and ideology. And it reflects the profound sedimentation of things. The humorous language, exaggerated and dramatic plot create positive image for the commodity and produce positive energy.

\section{REFERENCES}

[1] Luobeier. On humor. Shanghai Social Sciences Press.Vol.24 (1990)No10,p182-183.

[2] Wang Xiaodong. A casual, instant attraction. Kyushu Press.,2002,p111-112.

[3] Li Meiling. Humor advertisement: a powerful drug to draw attention. Beijing Press, 2003, p89-90. 